BMJ Open

Diabetes

Research

\& Care

\title{
GABA induces a hormonal counter- regulatory response in subjects with long-standing type 1 diabetes
}

\author{
Daniel Espes (1) , ${ }^{1,2}$ Hanna Liljebäck, ${ }^{3,4}$ Henrik Hill, ${ }^{5}$ Andris Elksnis, ${ }^{3}$ \\ José Caballero-Corbalan, ${ }^{4}$ Bryndis Birnir, ${ }^{3}$ Per-Ola Carlsson ${ }^{3,4}$
}

To cite: Espes D, Liljebäck H, Hill $\mathrm{H}$, et al. GABA induces a hormonal counter-regulatory response in subjects with long-standing type 1 diabetes. BMJ Open Diab Res Care 2021;9:e002442. doi:10.1136/ bmjdrc-2021-002442

\section{- Additional supplemental material is published online only. To view, please visit the journal online (http://dx.doi. org/10.1136/bmjdrc-2021- 002442).}

$\mathrm{DE}$ and $\mathrm{HL}$ are joint first authors.

Received 22 June 2021 Accepted 29 September 2021

Check for updates

(c) Author(s) (or their employer(s)) 2022. Re-use permitted under CC BY. Published by BMJ.

${ }^{1}$ Department of Medical Cell Biology, Science for Life Laboratory, Uppsala University, Uppsala, Sweden

${ }^{2}$ Department of Medical Sciences, Science for Life Laboratory, Uppsala University, Uppsala, Sweden

${ }^{3}$ Department of Medical Cell Biology, Uppsala University, Uppsala, Sweden

${ }^{4}$ Department of Medical Sciences, Uppsala University, Uppsala, Sweden

${ }^{5}$ Department of Women's and Children's Health, Uppsala University, Uppsala, Sweden

Correspondence to Professor Per-0la Carlsson; per-ola.carlsson@mcb.uu.se

\section{ABSTRACT}

Introduction Experimentally, gamma-aminobutyric acid (GABA) has been found to exert immune-modulatory effects and induce beta-cell regeneration, which make it a highly interesting substance candidate for the treatment of type 1 diabetes (T1D). In many countries, including those in the European Union, GABA is considered a pharmaceutical drug. We have therefore conducted a safety and dose escalation trial with the first controlled-release formulation of GABA, Remygen (Diamyd Medical).

Research design and methods Six adult male subjects with long-standing T1D (age 24.8 \pm 1.5 years, disease duration $14.7 \pm 2.2$ years) were enrolled in an 11-day dose escalation trial with a controlled-release formulation of GABA, Remygen. Pharmacokinetics, glucose control and hormonal counter-regulatory response during hypoglycemic clamps were evaluated at every dose increase (200 mg, $600 \mathrm{mg}$ and $1200 \mathrm{mg}$ ).

Results During the trial there were no serious and only a few, transient, adverse events reported. Without treatment, the counter-regulatory hormone response to hypoglycemia was severely blunted. Intake of $600 \mathrm{mg}$ GABA more than doubled the glucagon, epinephrine, growth hormone and cortisol responses to hypoglycemia.

Conclusions We find that the GABA treatment was well tolerated and established a counter-regulatory response to hypoglycemia in long-standing T1D. Further studies regarding not only the clinical potential of Remygen for beta-cell regeneration but also its potential use as hypoglycemic prophylaxis are warranted.

Trail registration number NCT03635437 and EudraCT2018-001115-73.

\section{INTRODUCTION}

Gamma-aminobutyric acid (GABA) is a mediator in the central nervous system (CNS) and in peripheral tissues with effects exerted through ionotropic GABA-A and GABA-C, as well as metabotropic GABA-B receptors. ${ }^{1}$ GABA is synthesized from glutamate by glutamic acid decarboxylase, a well-known autoantigen in type 1 diabetes (T1D). ${ }^{2}$ In the adult brain, GABA is the main inhibitory neurotransmitter, while its peripheral effects vary depending on the tissue. Outside the CNS, GABA is found at the highest concentrations in beta-cells and immune cells. ${ }^{34}$

\section{Significance of this study}

What is already known about this subject?

$\Rightarrow$ Gamma-aminobutyric acid (GABA) has, in experimental studies, been found to exert immune-modulatory effects and induce beta-cell regeneration, which make it a highly interesting substance candidate for the treatment of type 1 diabetes (T1D).

$\Rightarrow$ Activation of the GABA-A receptor by benzodiazepines has been found to blunt the counter-regulatory response to hypoglycemia.

$\Rightarrow$ In many countries, including those in the European Union, GABA is considered a pharmaceutical drug.

What are the new findings?

$\Rightarrow$ GABA treatment is well tolerated in subjects with T1D.

$\Rightarrow$ GABA can paradoxically establish a counterregulatory response to hypoglycemia in longstanding T1D.

How might these results change the focus of research or clinical practice?

$\Rightarrow$ GABA has a potential use as hypoglycemic prophylaxis in clinical practice in addition to its potential beta-cell regenerative effects.

Most immune cells express GABA receptor subunits and the metabolic machinery required for GABA metabolism. GABA exerts a predominantly inhibitory effect on immune cells by inhibiting the production of inflammatory cytokines. ${ }^{56}$ GABA receptor activation also enhances regulatory $\mathrm{T}$ cells, contributing to its immunosuppressive functions. ${ }^{7}$ In addition to beta-cells, GABA-A receptors are also expressed in a number of peripheral tissues, including the pituitary, chromaffin cells in the adrenal medulla and hepatocytes. ${ }^{8-10}$ In experimental studies with rodent and human beta-cells, GABA has been shown to reverse diabetes by stimulating beta-cell regeneration, both through beta-cell proliferation and, although more controversial, transdifferentiation. ${ }^{1-13}$ The combined immunemodulatory and beta-cell effects make GABA 
a highly interesting candidate for the treatment of T1D. However, in many countries, including those in the European Union, GABA is considered a pharmaceutical drug. In this initial safety and dose escalation study, we have evaluated short-term GABA treatment in subjects with T1D as a first step toward testing the potential of GABA as a beta-cell regenerative treatment.

\section{METHODS}

Ethics and study design

GABA is considered a pharmaceutical drug within the European Union. All participants were provided oral and written information and signed a written consent prior to inclusion in the study.

The study was an open-label, investigator-driven phase I clinical trial, primarily assessing the safety of a controlledrelease formulation of GABA, Remygen (Diamyd Medical, Stockholm, Sweden), in adult male subjects with long-standing T1D. GABA was dosed in three steps: low $(200 \mathrm{mg})$, medium $(600 \mathrm{mg})$ and high $(1200 \mathrm{mg})$ dose, with subsequent pharmacokinetic evaluation. Remygen was administered orally as a single daily dose to be taken under fasting conditions in the morning and each dose was administered for three consecutive days. The study period consisted of visits at the hospital for 11 consecutive days. Sample size was decided after dialogue with the Swedish Medical Products Agency. The study included two mixed meal tolerance tests (MMTT), four hypoglycemic clamps and three pharmacokinetic evaluations. All study visits were conducted at Uppsala University Hospital. A detailed study design and all inclusion/exclusion criteria can be found at ClinicalTrials.gov.

\section{Safety monitoring}

All subjects underwent general and neurological examinations, as well as blood sampling for laboratory testing, at multiple time points during the safety trial. The study was monitored by Uppsala Clinical Research Center. An external Data Safety Monitoring Board reviewed the data.

\section{Laboratory testing}

Laboratory tests included metabolic parameters (glucose, hemoglobin Alc (HbAlc) and C peptide), hematology status, renal function and markers of liver injury (aspartate transaminase (AST), alanine aminotransferase (ALT), alkaline phosphate, bilirubin). During the hypoglycemic clamp, the counter-regulatory hormones glucagon, growth hormone $(\mathrm{GH})$, cortisol, epinephrine and norepinephrine were analyzed. Routine blood samples were analyzed at the central laboratory of Uppsala University Hospital. Epinephrine and norepinephrine concentrations were analyzed at Karolinska University Hospital laboratory. C peptide concentrations were also analyzed with an ultrasensitive $\mathrm{C}$ peptide ELISA (Mercodia, Uppsala, Sweden). Glycemic control was monitored by flash glucose monitoring (FGM) (FreeStyle Libre, Abbott Laboratories, Chicago, Illinois, USA).

\section{Pharmacokinetics of GABA}

GABA concentrations in plasma were determined the first day of every dose increase at $0,30,60,120,180,300$ min and 24 hours (nadir value) after GABA administration. GABA levels were analyzed by mass spectrometry at the Mass Spectrometry Based Metabolomics Facility at Uppsala University with a method approved by the US Food and Drug Administration.

\section{Mixed meal tolerance test}

An MMTT was performed after overnight fasting at baseline and at day 11, that is, last day of treatment with 1200 mg GABA. C peptide and glucose levels were measured at $0,15,30,60,90$ and $120 \mathrm{~min}$ after ingestion of $6 \mathrm{~mL} /$ $\mathrm{kg}$ (maximum $360 \mathrm{~mL}$ ) Resource Protein (Nestlé Health Science, Switzerland).

\section{Hypoglycemic clamp}

A hypoglycemic clamp was performed after overnight fasting at baseline and at each GABA dosage step. An individualized insulin infusion dose was calculated based on body weight $(2 \mathrm{mIE} / \mathrm{kg} / \mathrm{min})$ and a separate glucose infusion was titrated to achieve and maintain euglycemia ( $5.5 \mathrm{mmol} / \mathrm{L}$ ) for $30 \mathrm{~min}$, followed by hypoglycemia $(2.5$ $\mathrm{mmol} / \mathrm{L}$ ) for $30 \mathrm{~min}$. Blood samples were collected at the end of each plateau. GABA was administrated $30 \mathrm{~min}$ before start.

\section{Endpoints}

The primary outcomes of the trial were (1) number of serious and adverse events (SAE/AE) and (2) changes in laboratory parameters, physical examinations and vital signs. The secondary outcomes were (1) C peptide response during MMTT determined as area under the curve (AUC), mean and peak values; and (2) hormonal counter-regulatory response. Additional variables such as fasting plasma $\mathrm{C}$ peptide, HbA1c, autoantibodies and number of self-reported hypoglycemic events were included in the general assessment.

\section{Statistical analysis}

Safety laboratory tests were compared with baseline with repeated measurements one-way analysis of variance (ANOVA) with Dunnett's post-hoc test. For FGM data a non-parametric one-way ANOVA with Dunn's multiple comparisons test was applied. Hormonal counterregulatory response under normoglycemic and hypoglycemic conditions was computed by multiple t-tests and corrected for multiple testing with the Holm-Sidak method. Data are presented as mean \pm SEM. P values $<0.05$ were considered statistically significant.

\section{RESULTS}

\section{Characteristics of the subjects}

Ten male subjects with T1D were screened, of whom four were excluded from participation in the study $(\mathrm{C}$ peptide $>0.12 \mathrm{nmol} / \mathrm{L}(\mathrm{n}=2)$, elevated AST/ALT $(\mathrm{n}=1)$ and difficult venous access $(n=1))$. Six subjects were 
Table 1 Descriptive data including autoantibodies of study participants at baseline

\begin{tabular}{|c|c|}
\hline Parameter & Subjects $(n=6)$ \\
\hline Male (\%) & 100 \\
\hline Age (years) & $24.8 \pm 1.5$ \\
\hline Age at onset (years) & $10.3 \pm 2.2$ \\
\hline T1D duration (years) & $14.7 \pm 2.2$ \\
\hline BMI (kg/m², ref: 20-25) & $22.6 \pm 1.4$ \\
\hline Hemoglobin (g/L, ref: $130-170)$ & $142.8 \pm 3.1$ \\
\hline Creatinine ( $\mu \mathrm{mol} / \mathrm{L}$, ref: $60-105)$ & $74.2 \pm 2.2$ \\
\hline Bilirubin ( $\mu \mathrm{mol} / \mathrm{L}$, ref: $5-25)$ & $14.4 \pm 2.0$ \\
\hline ALT ( $\mu$ kat/L, ref: 0.15-1.1) & $0.37 \pm 0.08$ \\
\hline AST ( $\mu$ kat/L, ref: $0.25-0.75)$ & $0.43 \pm 0.09$ \\
\hline ALP ( $\mu$ kat/L, ref: 0.6-1.8) & $1.4 \pm 0.1$ \\
\hline HbA1c (mmol/mol, ref: 27-42) & $64.8 \pm 6.2$ \\
\hline Fasting $C$ peptide $>0.01 \mathrm{nmol} / \mathrm{L}(\mathrm{n})$ & 1 \\
\hline GAD positive (n) & 3 \\
\hline IA2 positive (n) & 4 \\
\hline \multicolumn{2}{|c|}{$\begin{array}{l}\text { Reference values are presented within brackets. } \\
\text { The cut-off for positive GAD autoantibodies was set to }>5 \text { IE/mL and for IA2 } \\
\text { to }>7.5 \mathrm{kE} / \mathrm{L} \text { according to clinical routine. } \\
\text { ALP, alkaline phosphate; ALT, alanine aminotransferase; AST, aspartate } \\
\text { transaminase; BMI, body mass index; GAD, glutamic acid decarboxylase; } \\
\text { HbA1c, hemoglobin A1c; IA2, Islet Antigen 2; ref, reference; T1D, type } 1 \\
\text { diabetes. }\end{array}$} \\
\hline
\end{tabular}

included and all completed the 11-day trial. All subjects had long-standing T1D (age $24.8 \pm 1.5$ years, disease duration $14.7 \pm 2.2$ years). Full descriptive data are presented in table 1 .

\section{Safety evaluation}

None of the patients had SAE and there were no AEs reported during treatment with the low dose, while four patients reported mild and transient AEs (mostly neurological sensations) at the medium and high dose of GABA (online supplemental table 1). Hemoglobin levels decreased when compared with baseline during the medium-dose and high-dose treatment, which was deemed to be related to the extensive blood sampling during the study (baseline 142.8 $\pm 3.1 \mathrm{~g} / \mathrm{L}$, low-dose $137.5 \pm 2.6 \mathrm{~g} / \mathrm{L}$, medium-dose 131.3 \pm 2.3 and high-dose $124.8 \pm 2.5, \mathrm{p}<0.001)$. Blood platelet and leukocyte counts were unaffected by GABA treatment. Also, ALT, AST, bilirubin and creatinine levels were unaffected, whereas alkaline phosphate levels slightly decreased during the high-dose treatment (data not shown). As expected, the GABA pharmacokinetics displayed increasing AUC levels at higher doses (online supplemental table 2).

\section{Metabolic parameters}

Five of the patients had undetectable $\mathrm{C}$ peptide levels when analyzed with the standard clinical assay (ie, $<0.01$ $\mathrm{nmol} / \mathrm{L}$ ), and both the fasting and stimulated levels were unaffected by short-term GABA treatment. When assessed by the ultrasensitive $\mathrm{C}$ peptide ELISA, three patients were found to have detectable $\mathrm{C}$ peptide under fasting conditions and one additional patient during stimulated conditions. The levels were, however, unaffected by the short-term GABA treatment (data not shown). Given the small sample size and limited study period, we could not detect any significant differences with regard to time in range, or time below range, when analyzing the FGM data (figure 1A).

\section{Response to hypoglycemia}

The patient with remaining $\mathrm{C}$ peptide displayed a normal hormonal counter-regulatory response to hypoglycemia at baseline, which was maintained under the GABA treatment (data not shown). In contrast, the five patients without detectable $\mathrm{C}$ peptide $(<0.01 \mathrm{nmol} / \mathrm{L})$ displayed absence of counter-regulatory response at baseline (figure 1B-F). During GABA treatment $(600 \mathrm{mg})$ a counter-regulatory response of glucagon, epinephrine, $\mathrm{GH}$, as well as cortisol occurred in response to hypoglycemia (figure 1B-F).

\section{DISCUSSION}

Short-term oral GABA treatment was not associated with any SAEs. AEs were registered in four subjects, but they were all mild and transient, mainly neurological sensations. In previous studies, fatigue and mild weakness have also been reported..$^{14}$ In another study, $3 \mathrm{~g}$ of GABA caused mild transaminase increases in $2 \%$ of study subjects. ${ }^{15}$ Glucose control was maintained during the study period and the frequency of hypoglycemia did not increase.

In contrast to previous studies in which activation of the GABA-A receptor by benzodiazepines has been found to blunt the counter-regulatory response, ${ }^{16}$ we paradoxically found that the hormonal counter-regulatory response to hypoglycemia was enhanced by GABA treatment. A tentative explanation for this difference in results is that GABA per se has limited capacity to cross the blood-brain barrier, while benzodiazepines easily cross to exert their effects in the CNS. The mechanism for the counter-regulatory failure induced by benzodiazepines has previously been shown to be lactate release in the ventromedial hypothalamus. ${ }^{17}$ Also, the metabolism of GABA and benzodiazepines differs, which could in turn impact the counter-regulatory response. The present study shows that if the peripheral effects of GABA are isolated, the hormonal counter-regulatory response instead become enhanced by yet unknown mechanisms. A possible explanation could be the activation of GABA-A receptors in other peripheral organs/tissues of importance for the hormonal counter-regulatory response. For instance, GABA-A receptor activation in chromaffin cells within the adrenal glands induces the secretion of catecholamines. ${ }^{9}$ The study period and sample size (number of subjects included) were, however, in this study too small to assess potential clinical benefits in hypoglycemia severity and frequency. 
A

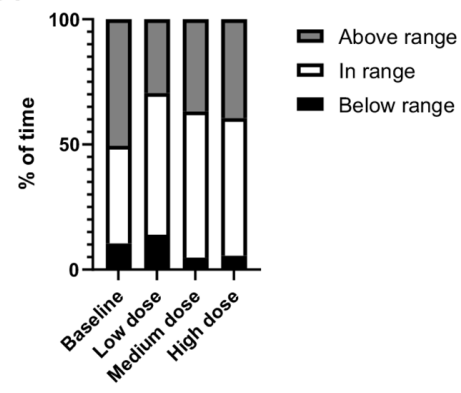

D

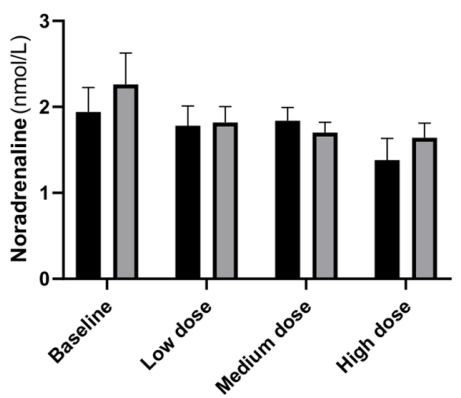

B

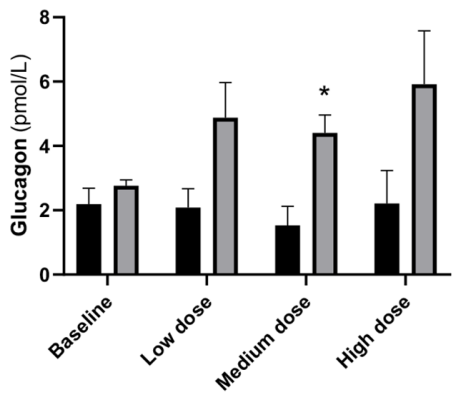

$\mathrm{E}$

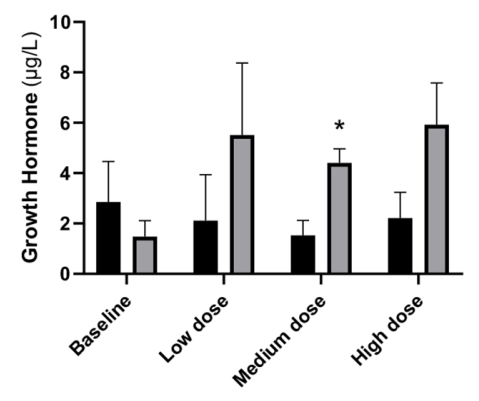

C

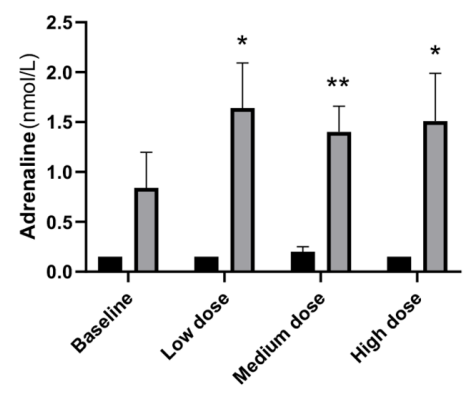

$\mathrm{F}$

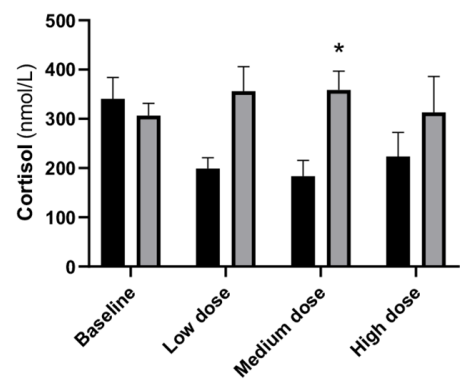

Figure 1 GABA treatment improves the counter-regulatory hormone response to hypoglycemia in type 1 diabetes. (A) Flash glucose monitoring for all subjects $(n=6)$ at baseline and during short-term oral treatment with GABA in increasing doses. (B-F) Hormonal counter-regulatory response during hyperinsulinemic hypoglycemic clamps. Glucose levels were regulated by an intravenous continuous rate of insulin and a variable rate of glucose in order to reach first a 30 min plateau with glucose levels of $5.5 \mathrm{mmol} / \mathrm{L}$, followed by a $30 \mathrm{~min}$ plateau at $2.5 \mathrm{mmol} / \mathrm{L}$. Blood samples were collected at the end of each plateau. The analysis contains data from the five subjects without detectable $C$ peptide $(<0.01 \mathrm{nmol} / \mathrm{L})$ in which the counter-regulatory response was blunted at baseline. Black bars represent normoglycemia $(5.5 \mathrm{mmol} / \mathrm{L})$ and gray bars hypoglycemic conditions $(2.5 \mathrm{mmol} / \mathrm{L})$. Data are presented as mean \pm SEM. ${ }^{*} \mathrm{P}<0.05$ and ${ }^{* *} \mathrm{P}<0.01$ compared with the normoglycemic levels at the respective occasion. GABA, gamma-aminobutyric acid.

We conclude that the controlled-release formulation of GABA (Remygen) can be considered a safe treatment in T1D and that a larger, long-term clinical trial is warranted in order to further study the clinical potential of GABA as a drug for beta-cell regeneration and, in view of the findings in this study, hypoglycemia protection.

Acknowledgements We are grateful for the great efforts and expert assistance by Karin Kjellström and Rebecka Hilmius (research nurses at Uppsala University Hospital). Diamyd Medical is gratefully acknowledged for providing Remygen. We are grateful for the expert assistance with GABA analysis by Professor Jonas Bergquist and Dr Kumari Ubhayasekera at the Mass Spectrometry Based Metabolomics Facility (Uppsala University, Sweden) and to Mercodia (Uppsala, Sweden) for their expert assistance with ultrasensitive $C$ peptide analysis.

Contributors P-OC, DE and BB designed the study. HL, DE, HH, AE, JC-C (until February 28,2019 ) and $P-O C$ performed the clinical assessments in the study. DE, $\mathrm{HH}$ and $\mathrm{P}-\mathrm{OC}$ researched the data, and $\mathrm{DE}, \mathrm{HL}$ and $\mathrm{P}-\mathrm{OC}$ wrote the manuscript. All authors critically reviewed the manuscript. $\mathrm{P}-\mathrm{OC}$ is the guarantor of this work.

Funding We are grateful for the financial support from Barndiabetesfonden, Vetenskapsrådet, Diabetesfonden, Exodiab and the Swedish Society for Medical Research.

Disclaimer Funders were not involved in the study design, acquisition, analysis and interpretation of data or writing of this article.

Competing interests DE and POC are listed as coinventors for a patent application submitted by Diamyd Medical, but do not have any financial interests in Diamyd Medical. None of the other authors have any conflicts of interest to declare.
Ethics approval The study was approved by both the Uppsala County Ethics Board (Dnr 2018/200/1) and the Swedish Medical Products Agency. The reported investigations were carried out in accordance with the principles of the Declaration of Helsinki as revised in 2013.

Provenance and peer review Not commissioned; externally peer reviewed.

Data availability statement Data are available upon reasonable request. The data sets generated during the current study can be made available from the corresponding author upon reasonable request.

Supplemental material This content has been supplied by the author(s). It has not been vetted by BMJ Publishing Group Limited (BMJ) and may not have been peer-reviewed. Any opinions or recommendations discussed are solely those of the author(s) and are not endorsed by BMJ. BMJ disclaims all liability and responsibility arising from any reliance placed on the content. Where the content includes any translated material, BMJ does not warrant the accuracy and reliability of the translations (including but not limited to local regulations, clinical guidelines, terminology, drug names and drug dosages), and is not responsible for any error and/or omissions arising from translation and adaptation or otherwise.

Open access This is an open access article distributed in accordance with the Creative Commons Attribution 4.0 Unported (CC BY 4.0) license, which permits others to copy, redistribute, remix, transform and build upon this work for any purpose, provided the original work is properly cited, a link to the licence is given, and indication of whether changes were made. See: https://creativecommons.org/licenses/by/4.0/.

ORCID iD

Daniel Espes http://orcid.org/0000-0001-8843-7941 


\section{REFERENCES}

1 Watanabe M, Maemura K, Kanbara K, et al. Gaba and gaba receptors in the central nervous system and other organs. Int Rev Cytol 2002;213:1-47.

2 Baekkeskov S, Aanstoot HJ, Christgau S, et al. Identification of the $64 \mathrm{~K}$ autoantigen in insulin-dependent diabetes as the gaba-synthesizing enzyme glutamic acid decarboxylase. Nature 1990;347:151-6.

3 Taniguchi H, Okada Y, Seguchi H, et al. High concentration of gamma-aminobutyric acid in pancreatic beta cells. Diabetes 1979;28:629-33.

4 Jin Z, Mendu SK, Birnir B. Gaba is an effective immunomodulatory molecule. Amino Acids 2013;45:87-94.

5 Bergeret M, Khrestchatisky M, Tremblay E, et al. Gaba modulates cytotoxicity of immunocompetent cells expressing gabaA receptor subunits. Biomed Pharmacother 1998;52:214-9.

6 Tian J, Chau C, Hales TG, et al. GABA(A) receptors mediate inhibition of T cell responses. J Neuroimmunol 1999;96:21-8.

7 Tian J, Dang H, Wallner M, et al. Homotaurine, a safe blood-brain barrier permeable $\mathrm{GAB}_{\mathrm{AA}}$-R-specific agonist, ameliorates disease in mouse models of multiple sclerosis. Sci Rep 2018;8:16555.

8 Hansen SL, Fjalland B, Jackson MB. Modulation of gabaA receptors and neuropeptide secretion by the neurosteroid allopregnanolone in posterior and intermediate pituitary. Pharmacol Toxicol 2003:93:91-7.

9 Harada K, Matsuoka H, Fujihara H, et al. Gaba signaling and neuroactive steroids in adrenal medullary chromaffin cells. Front Cell Neurosci 2016;10:100.
10 Erlitzki R, Gong Y, Zhang M, et al. Identification of gammaaminobutyric acid receptor subunit types in human and rat liver. Am J Physiol Gastrointest Liver Physiol 2000;279:G733-9.

11 Tian J, Dang H, Chen Z, et al. $\gamma$-Aminobutyric acid regulates both the survival and replication of human $\beta$-cells. Diabetes 2013;62:3760-5.

12 Untereiner A, Xu J, Bhattacharjee A, et al. $\gamma$-aminobutyric acid stimulates $\beta$-cell proliferation through the mTORC1/p70S6K pathway, an effect amplified by Ly49, a novel $\gamma$-aminobutyric acid type A receptor positive allosteric modulator. Diabetes Obes Metab 2020;22:2021-31.

13 Ben-Othman N, Vieira A, Courtney M, et al. Long-term gaba administration induces alpha cell-mediated beta-like cell neogenesis. Cell 2017;168:e11:73-85.

14 Cavagnini $F$, Invitti $C$, Pinto $M$, et al. Effect of acute and repeated administration of gamma aminobutyric acid (gaba) on growth hormone and prolactin secretion in man. Acta Endocrinol 1980;93:149-54.

15 Otomo E, Araki G, Mori A, et al. Clinical evaluation of gaba in the treatment of cerebrovascular disorders. multi-center double-blind study in comparison with pyrithioxine and placebo. Arzneimittelforschung 1981;31:1511-23.

16 Hedrington MS, Mikeladze M, Tate DB, et al. Effects of $\gamma$-aminobutyric acid a receptor activation on counterregulatory responses to subsequent exercise in individuals with type 1 diabetes. Diabetes 2016;65:2754-9.

17 Chan O, Paranjape SA, Horblitt A, et al. Lactate-induced release of gaba in the ventromedial hypothalamus contributes to counterregulatory failure in recurrent hypoglycemia and diabetes. Diabetes 2013;62:4239-46. 